University of Nebraska - Lincoln

DigitalCommons@University of Nebraska - Lincoln

9-1979

\title{
High school students' images of geography: An exploratory analysis
}

\author{
Raymond Hubbard \\ University of Washington - Seattle Campus \\ Robert Stoddard \\ University of Nebraska - Lincoln, rstoddard1@unl.edu
}

Follow this and additional works at: https://digitalcommons.unl.edu/geographyfacpub

Part of the Geography Commons

Hubbard, Raymond and Stoddard, Robert, "High school students' images of geography: An exploratory analysis" (1979). Geography Faculty Publications. 12.

https://digitalcommons.unl.edu/geographyfacpub/12

This Article is brought to you for free and open access by the Geography Program (SNR) at DigitalCommons@University of Nebraska - Lincoln. It has been accepted for inclusion in Geography Faculty Publications by an authorized administrator of DigitalCommons@University of Nebraska - Lincoln. 


\section{High school students' images of geography: an exploratory analysis}

Almost since its introduction into American high schools and colleges, geography has been plagued with the problem of justifying its existence as a bona fide academic discipline.' This identity problem has been attributed to a variety of circumstances and conditions, including the common explanation that geography is a virtually unbounded discipline. For many individuals this unduly amorphous characteristic is particularly burdensome when attempts are made to define the subject matter of geography. This, in turn, hampers the presentation of a clear and distinct image of the discipline to nongeographers. Closely related to the problem of geography's diverse content and delineation is the multitude of meanings associated with its very name. Because "geography" conveys different notions from one individual to another, the resulting combination of perspectives frequently leads to an indistinct image of its domain. ${ }^{2}$

Despite the fact that some geographers may wish that the discipline had a narrower emphasis and a different title, there is little likelihood that such changes will occur in the near future. Consequently, it behooves geographers to investigate the manner in which images pertaining to the subject are formulated and to gain some appreciation about their composition. Because of the almost universal nature of precollege schooling in the United States, it

'For an appraisal of the critical implications of such comments for the geographical community, see J. W. R. Whitehand, "The Fault, Dear Brutus, Is . . . in Ourselves," Area 9 (1977): 225-28.

'W. J. Brown, "A Lawyer Looks at the Name Geography," Professional Geographer 13 (1961): 16-19; B. Floyd, "On Reversing the Image of a Simplistic Geography: The Task of SocioEconomic Geography (Geonomics)," Journal of Geography 70 (1971): 84-90.

Dr. Hubbard is Visiting Assistant Professor in the Department of Geography at the University of Washington in Seattle. Dr. Stoddard is Associate Professor in the Department of Geography at the University of Nebraska in Lincoln. would appear that impressions regarding geography are primarily nurtured and developed at elementary and secondary levels. Factors that perpetuate misconceptions of geography may include the differential quality of both teacher training and textbooks. Teachers who have received most of their geography training in colleges of education and have taken few, if any, college courses from professional geographers are more likely to present a "traditional" image of geography, rather than a contemporary one, to their students. ${ }^{3}$ Similarly, the frequent use of textbooks written by nongeographers tends to project a distorted view concerning the nature of the discipline.4

The impressions of geography that elementary and high school students possess may affect the quality and extent of their subsequent participation in matters involving geographic principles in community or college activities. Well-designed geography programs in secondary schools could provide students with an understanding of locational processes that aid in their later role as active citizens in their communities (e.g., evaluating zoning changes, planning local land use, and locating potential hazards to the environment). Similarly, the perspectives of high school graduates undoubtedly affect their initial involvement with the discipline at the college level.

For both situations it is important to have access to information on the images of geography that high school students acquire. As Carswell has noted, "We need to measure attitudes as well as knowledge [about geography because] the

'R. C. Miller, "High School Geography in Nebraska," Journal of Geography 47 (1948): $8-17$, reported that 80 percent of those teaching geography had "inadequate training" in the 1940s. More recently, R. C. Anderson, "Geography in Secondary Education" (Ed.D. diss., University of Nebraska, 1963), p. 144, stated that "the inadequate geographical preparation of social studies teachers" was one of the major explanations for geography's "failure to achieve widespread status as a social study in grades nine through twelve."

"R. H. Jackson, "The Persistence of Outmoded Ideas in High School Geography Texts," Journal of Geography 75 (1976): 399-408; Anderson, "Geography in Secondary Education." 
likelihood that a student will use his knowledge of geography is influenced by his attitude toward the subject."5 In reference to the college student, Hastings, Wardrop, and Gooler have suggested that "it might be of use in the long run improvement of college geography to study student outcomes across a wide range of beginning courses in terms of beliefs and feelings about geography."

This paper attempts to evaluate the "images" of geography possessed by high school students. Do students consider geography to be of intrinsic value as a conceptual discipline, or do they feel that it involves nothing more than memorizing and regurgitating facts? Does geography possess any practical utility? Will geography give students insights into the world around them? Do students view geography as an easy course? Is geography considered a discipline worth pursuing at the college level? In view of the heterogeneous nature of the field, are students capable of defining the subject matter of geography? Answers to at least some of these questions are presented in this study; however, this research is suggestive rather than definitive because of limitations in the sample and restrictions in the measuring techniques.

\section{THE RESEARCH DESIGN}

In an effort to gauge students' attitudes or images of geography, a Likert-type rating scale consisting of 30 statements was employed (table 1). ${ }^{7}$ Ten of the statements were constructed to ascertain the knowledge $(K)$ that students possessed about the subject matter of geography (i.e., with what is geography primarily concerned?). The remaining 20 statements were designed to elicit responses that would indicate the attitudes (A) of the students toward geography's utility or value and their impression of the way in which it was taught ( $T$ ). Presumably, the students' images of geography would be affected by the manner in which the subject matter was handled, and thus images and teaching might be expected to be highly interrelated. The 30 statements were presented to students in a random order; some carried a "positive" image, and others a "negative" one. Subsequently, to ensure that scoring was consistent, a value of " 5 " was regarded as "favorable to geography" and a value of "1" as "unfavorable to geography."

${ }^{3}$ R. J. B. Carswell, "Evaluation of Affective Learning in Geography Education" in Evaluation in Geographic Education, The 1971 Yearbook of the National Council for Geographic Education, ed. D. G. Kurfman (Belmont, Calif.: Fearon Publishers, 1970), pp. 108-09.

'J. T. Hastings, J. L. Wardrop, and D. Gooler, Evaluating Geography Courses: A Model with Illustrative Applications, Association of American Geographers, Commission on College Geography, Technical Paper No. 3 (Washington, D.C., 1970), p: 31.

'R. Likert, "A Technique for the Measurement of Attitudes," Archives of Psychology 140 (1932): 44-53.

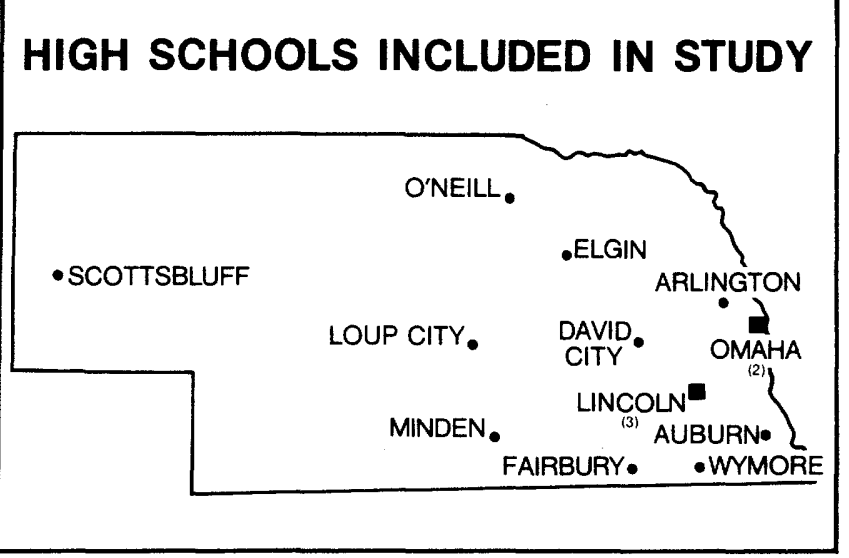

Figure 1

Students enrolled in geography classes in fifteen Nebraska high schools served as subjects for the study. Although the classes were chosen to achieve a reasonable degree of geographic dispersion throughout the state (fig. 1), an areal random sampling method was not employed primarily because many secondary schools in Nebraska do not offer a geography course. ${ }^{8}$ The results are based on 694 responses to the questions by students in grades nine through twelve during the spring semester of $1972 .^{\circ}$

\section{KNOWLEDGE, TEACHING, AND ATTITUDES}

Carswell has proposed that "there seem to be at least three categories of attitudinal information that would be of use to us. These are (1) attitudes toward geography as a subject, (2) internalization of attitudes geographers hold, and (3) attitudes toward the substantive content of geography courses." 10 In this study, attitudes toward the substantive content of geography should be elicited by the first ten statements in table 1 . Many of these statements reflect the popular image of geography, such as statements 1,2, 3, 4, and 5 , in which geography is perceived as consisting of "a bunch of facts." That popular image is not necessarily incorrect because many geographers believe that a certain amount of basic factual data should be presented to students. The need for these data is readily apparent from studies over the past half century. As long ago as 1929, Bengston reported on a project involving 932 eleventh and twelfth grade

\footnotetext{
'Approximately one-third of the high schools in Nebraska offered geography as a distinct subject during 1977-78. This sample included only students enrolled in a high school geography class.

Although the empirical data were collected in 1972, there appears to be no compelling reason why significant changes in high school students' images should have occurred between then and the present.

${ }^{10}$ Carswell, "Evaluation of Affective Learning," p. 111.
} 
TABLE 1

Likert-type scale for images of geography and resulting mean scores

\begin{tabular}{|c|c|c|c|}
\hline $\begin{array}{l}\text { CLASS OF } \\
\text { STATEMENT }\end{array}$ & SCORING & STATEMENTS & $\begin{array}{l}\text { MEAN } \\
\text { SCORES }\end{array}$ \\
\hline $\begin{array}{l}K \\
K \\
K \\
K \\
K \\
T \\
T \\
T \\
T \\
T \\
T \\
T \\
T \\
A \\
A \\
A \\
A \\
A \\
A \\
A \\
A \\
A \\
A \\
A \\
A\end{array}$ & $\begin{array}{l}5 \\
5 \\
5 \\
5 \\
1 \\
\\
1 \\
5 \\
5 \\
5 \\
5 \\
1 \\
1 \\
5 \\
5 \\
1 \\
5 \\
5 \\
1 \\
1 \\
5 \\
5 \\
1 \\
5 \\
\end{array}$ & $\begin{array}{l}\text { 1. Drawing maps is what geography is all about. } \\
\text { 2. Geography is mainly concerned with physical features. } \\
\text { 3. Geography deals with the stories of people who travel in foreign lands. } \\
\text { 4. Knowing about different regions is the most important part of geography. } \\
\text { 5. Geography is nothing more than memorizing the countries and their } \\
\text { capital cities. } \\
\text { 6. Cities are of no concern to geographers. } \\
\text { 7. Geography is all about people around the world. } \\
\text { 8. Geography is the study of man's adapting to his physical environment. } \\
\text { 9. Geography's primary interest is explaining the location of things. } \\
\text { 10. The study of "man" and geography are two words for the same thing. } \\
\text { 11. Geography should not be taught in high schools. } \\
\text { 12. Geography does not teach anything useful. } \\
\text { 13. Geography should be a required subject for high school graduation. } \\
\text { 14. Geography should be given more emphasis in high schools. } \\
\text { 15. Geography courses are poorly organized. } \\
\text { 16. Geography should use more visual aids. } \\
\text { 17. Geography teachers are good teachers. } \\
\text { 18. Geography courses cover too many different things. } \\
\text { 19. Geography is a boring subject. } \\
\text { 20. Geography is interesting. } \\
\text { 21. Geography is a "fun" course. } \\
\text { 22. Geography is not a science. } \\
\text { 23. Geography is a conceptual subject. } \\
\text { 24. Geography is a logical subject. } \\
\text { 25. Geography would be a useful college major. } \\
\text { 26. Geography is an easy subject. } \\
\text { 27. Geography is helpful in understanding current affairs. } \\
\text { 28. Knowing about geography will not help get a job. } \\
\text { 29. Geography can be used to help solve the ecology crisis. } \\
\text { 30. Geography is nothing more than learning a bunch of facts. }\end{array}$ & $\begin{array}{l}2.219 \\
2.882 \\
2.562 \\
3.311 \\
\\
4.130 \\
4.040 \\
3.548 \\
3.510 \\
3.007 \\
3.316 \\
3.855 \\
4.135 \\
2.712 \\
2.765 \\
3.545 \\
3.478 \\
3.236 \\
3.169 \\
3.196 \\
3.300 \\
2.928 \\
3.220 \\
3.166 \\
3.754 \\
3.190 \\
2.741 \\
3.853 \\
3.516 \\
3.458 \\
3.507\end{array}$ \\
\hline
\end{tabular}

students studying American history at 36 high schools in Nebraska; he discovered that the average student could correctly answer only about one-third of 65 geography questions. ${ }^{11} \mathrm{~A}$ lack of basic knowledge concerning place-names was reported in 1952 by Williams, who found that university students frequently could not identify the states on a blank outline map of the United States. Indeed, for some thirteen universities across the country, the average total percentage of error was 28.8. ${ }^{12}$ In a contemporary article, Wise

"N. A. Bengston, "High School Geography-To Be Or Not To Be," School Science and Mathematics 29 (1929): 693-701.

${ }^{12} \mathrm{~K}$. J. Williams, "A Survey of the Knowledge of Incoming Students in College Geography," Journal of Geography 51 (1952): 157-62. reported that teacher education students at Lakehead University in 1971 and 1973 were able to associate less than 55 percent of the world's largest cities with the country in which they are located. ${ }^{13}$

Clearly, if factual place-name information is lacking at the introductory college level, then high schools should be providing some of this training. Such information should be presented within a more conceptual framework than has traditionally been the case, however, since "facts" perceived as unrelated and irrelevant are rapidly lost from memory. As Bacon has noted, "Few important understandings were acquired by youngsters who

\footnotetext{
"John H. Wise, "Student Deficiency in Basic World Knowledge," Journal of Geography 74 (1975): 477-88.
} 
came to feel that the study of geography required little more than the memorization of seemingly unimportant lists of places and products. Certainly such exercises offered little intellectual challenge."14

In addition to those pertaining to factual information, table 1 includes statements expressing the nature of the domain with which geographers are concerned. Students should be made aware that geography is a discipline that attempts to explain the location of various phenomena by asking the question "why there?" rather than only "where?" 15 Also, students should realize that geography devotes much attention to the relationships and interaction between people and their physical environment. ${ }^{18}$ (See statements 7,9 , and 8 respectively.) With reference to geography, Kurfman indicated that

the base of the hierarchy consists of a great variety of knowledge objectives from knowledge of very specific information, such as naming state capitals, to knowledge of generalizations and concepts, such as influences on the locations of cities and cultural diffusion. This lowest level of objectives puts considerable emphasis on students recalling or remembering facts, terms and generalizations. Most of the questions in achievement tests measure this type of objective. teachers should place their emphasis on the development of higher level cognitive abilities. Above the level of remembering knowledge, in ascending order of complexity, are the abilities of comprehension, application, analysis, and evaluation."

Thus, once a student acquires a reasonable grasp of the variables that geographers study and of the interrelationships among them, that student is in a better position to evaluate the nature and utility of geography as a subject. In other words, the student formulates an image about geography. There is, however, no direct correlation between

"P. Bacon, "An Introduction to Geography in the Curriculum" in Curriculum Guide for Geographic Education, ed. W. Hill (Normal, III.: National Council for Geographic Education, 1964), p. 8. Similarly, J. Hugh McTeer, "High School Students' Attitudes toward Geography," Journal of Geography 78 (1979): 59 , found that many high school geography classes taught in northwestern Georgia consisted mainly of rote memorization.

${ }^{15}$ See, for example, N. Helburn, "The Educational Objectives of High School Geography," Journal of Geography 67 (1968): 275. See also W. D. Pattison, "The Educational Purposes of Geography" in Evaluation in Geographic Education, The 1971 Yearbook of the National Council for Geographic Education, ed. D. G. Kurfman (Belmont, Calif.: Fearon Publishers, 1970), p. 19.

"Helburn, "Educational Objectives of High School Geography"; S. Wood, "An Evaluation of Achievement Tests in Geography" in Evaluation in Geographic Education, The 1971 Yearbook of the National Council for Geographic Education, ed. D. G. Kurfman (Belmont, Calif.: Fearon Publishers, 1970), p. 136.

${ }^{17 D}$. G. Kurfman, "Evaluation Developments Useful in Geographic Education" in Evaluation in Geographic Education, The 1971 Yearbook of the National Council for Geographic Education (Belmont, Calif.: Fearon Publishers, 1970), p. 4-5. an increase in subject area knowledge and an increase in positive attitudes toward that subject area. $^{18}$ Students might possess a meager knowledge of geography, yet at the same time express a favorable attitude toward it. It seems reasonable, nevertheless, to assume that greater knowledge and familiarity with a subject place individuals in a better position to make a rational decision about their impressions of that discipline, whether positive or negative.

In order to gauge students' images of the nature and use of geography, twelve statements (19 through 30 ) consisting of both positive and negative attitudes have been included in table 1. Some of the "favorable to geography" statements (23 and 24) present geography as a conceptual subject, which is one of the aims of the High School Geography Project. ${ }^{19}$ Statements about the practical utility of geography are included as statements 27 and $29 .{ }^{20}$ Other practical considerations are put forward in statement 25, while the stimulating aspects of geography are hinted at in items 20,21 , and 26 . Negative statements (22 and 30 ) suggest a lack of stimulating and conceptual characteristics of the discipline. Statement 28 refers to a view of geography as an impractical subject.

The third set of items are those connected with the manner in which the subject is taught. It appears plausible to hypothesize that students' images of geography are shaped not only by the subject matter itself, but also by the way in which this information is communicated from teacher to student. Consequently, items 15, 16, 17, and 18 have been incorporated to tap the students' impressions of how geography is taught. Also, statements $11,12,13$, and 14 echo the pleas for more geography in the curriculum of high schools where students lack a geographic awareness. ${ }^{21}$

The image of geography, therefore, was measured by statements dealing with these three hypothesized components: students' knowledge of geography, their attitudes toward geography, and their perceptions of the way the subject has been taught.

\footnotetext{
${ }^{18}$ Carswell, "Evaluation of Affective Learning," p. 116

"Helburn, "Educational Objectives of High School Geog. raphy," pp. 280-81.

${ }^{20}$ For example, Bacon, "An Introduction to Geography in the Curriculum," states that ". . . geography in the school curriculum is a major source of the child's acquisition of tools and skills that will help him at world understanding"; also see H. J. Warman, "New Goals in Geographic Education," Social Education 26 (1962): 198.

${ }^{21}$ Anderson, "Geography in Secondary Education," p. 144; R. C. Anderson, "High School Geography: Retrospect and Prospect," Journal of Geography 65 (1966): 103-08; N. Bengston, "Geography as an Element in General Education," Journal of Geography 57 (1958): 121-31; H. Zadanowski, "Geographic Awareness of Eleventh Grade U.S. History Students," Journal
} of Geography 69 (1970): 475-79. 


\section{MEAN SCORES ON IMAGES OF GEOGRAPHY}

An examination of the mean scores reveals valuable information relating to the general image of geography held by the sampled students. In scoring the statements in table 1 , we assigned a value of " 5 " to each statement considered "favorable to geography"; consequently, a geographer would hope that the mean score for the 694 responses on each statement would approach 5 . Certain of the statements may be ambiguous, however. This is particularly true for some of the "knowledge" statements based on popular misconceptions regarding the content of geography. For example, how "favorable" is a "strongly agree" response to statement 1 , which concerns map-drawing abilities? Similarly, if a student agrees that geography deals mainly with physical features (statement 2), does this necessarily constitute a positive image of geography? Although a mean score larger than 3.00 (i. e., midway between 5 and 1) may be interpreted generally as being "favorable to geography," this is not equally true for all statements. For an informative comparison of mean scores, therefore, the content of each statement should be examined.

Students appear to have discriminated reasonably well on the ten "knowledge" items. They disagree that geography is concerned only with memorizing place-names (a mean of 4.130 on statement 5) and that it excludes an examination of cities (a mean of 4.040 on statement 6). Also, they tend to disagree that geography's chief function involves drawing maps (a mean of 2.219 on statement 1). The mean scores for other "knowledge" statements, including the declaration in statement 9 that geography's primary interest is in explaining the location of phenomena, hover around the neutral value of 3.00 . According to the mean response to statement 9 (3.007), students seem to be less able to discern what geography is than what geography is not.

The two statements regarding teaching that have the greatest mean score deviation from 3.00 deal with the usefulness of geography (statement 12 with a mean of 4.135 ) and whether it should be taught in high school (statement 11 with a mean of 3.855). The remainder of the mean scores are closer to a neutral position. Again, the difficulty in interpreting some of the statements themselves as favorable toward geography (e. g., statement 16 might be scored in either direction) should be noted.

The mean scores are less helpful in interpreting the "attitude" statements. In general, students believe geography helps in understanding current affairs (statement 27: 3.853) and is a logical subject (statement 24: 3.754 ). As a group, however, the students' other responses reveal neither a positive nor a negative reaction to geography (e. g., statement 20 rates 3.300 , and statement 21 yields 2.928 ).

While table 1 gives some useful summary information on the images that high school students hold about geography, it reveals little about the complexities of the interrelationships among the statements.

\section{EVALUATING IMAGE DIMENSIONS:} THE USE OF PRINCIPAL COMPONENTS ANALYSIS

Because there are obvious limitations involved in attempting to evaluate the images of geography from 30 average scores, extending the analysis of images beyond that level is necessary. Throughout this paper, we have stressed that students' "images" of geography may be identified by their reactions to statements (variables) relating to knowledge; teaching methods; and attitudes about the nature, scope, and utility of geography. The 30 statements were assigned a priori to each of these groups. However, do these groups exist in the minds of the students? Are the relationships subjectively postulated in this paper in fact borne out by an analysis of the data? Is it possible to derive groups of statements that collectively constitute meaningful constructs or concepts that aid in the interpretation of images of geography? In summary, can a smaller number of intelligible factors account for the variation in scores among the 30 statements?

A principal components model was selected to collapse the 30 existing statements into a smaller, and therefore more manageable, number of dimensions (factors) that would describe and account for the relationships and variations in high school students' images of geography. This particular model tests the hypothesis that images of geography are composed of three fundamental groups of variables relating to (1) knowledge about the subject matter of geography, (2) teaching of geography, and (3) attitudes toward geography.

For those unfamiliar with this statistical technique, the primary elements of principal components analysis, particularly as they relate to subsequent interpretation and discussion, will be reviewed briefly. ${ }^{22}$ The scores for each statement can be summarized by their mean and variance values, where the latter number refers to the average amount of deviation or dispersion around the mean. These variances can be statistically manipulated in numerous ways; for example, they can be summed to give a total variance and expressed as percentages of that total variance. Also, the variance from student responses can be apportioned in an alternative manner, including

\footnotetext{
${ }^{22}$ For an additional explanation of the statistical program, the reader should consult Joe-On Kim, "Factor Analysis" in Statistical Package for the Social Sciences, 2nd ed., edited by N. H. Nie et al. (New York: McGraw-Hill, 1975), pp. 468-514.
} 
COMPONENTS OF THE IMAGE OF GEOGRAPHY

HELD BY NEBRASKA HIGH SCHOOL STUDENTS

Component 1: Attitude-Teaching Relationship

Statement Number

12
24
11
30

Geography does not teach anything useful.

Geography is a logical subject.

Geography should not be taught in high school.

Geography is nothing more than learning a bunch of facts.

Component 1 accounts for 51.4 percent of the common variance.

Eigenvalue $=4.882$

Component 2: Knowledge of Subject Matter

Statement Number

Component 2 accounts for 13.3 percent of the common variance.

Eigenvalue $=1.262$

$\begin{array}{cc}\begin{array}{c}\text { Class of } \\ \text { Statement }\end{array} & \text { Loading } \\ \text { T } & .590 \\ \mathrm{~A} & .511 \\ \mathrm{~T} & .492 \\ \mathrm{~A} & .419\end{array}$

$\begin{array}{cc}\begin{array}{c}\text { Class of } \\ \text { Statement }\end{array} & \text { Loading } \\ \text { K } & .561 \\ \text { K } & .504 \\ \text { K } & .400\end{array}$

Figure 2

one that combines similar variances (statements). Because several statements deal with essentially the same factor (dimension/aspect/component), these can be grouped together without destroying the variance observed in the total set. In contrast to those approaches that make prior assumptions about the three components (knowledge, teaching, and attitudes), principal components analysis is a technique that groups variables that are statistically similar. The statistical manipulation (in this study by varimax rotation) apportions variance in a new way and identifies relationships between the original variables and the newly formed components. The amount of variance associated with each component is given by an eigenvalue, and the correlation between the original statement scores and those of each component is expressed as a loading. These data allow the researcher to evaluate the success of the grouping procedure and to interpret the nature of the components.

The principal components analysis extracted two identifiable components that account for almost 65 percent of the common variance in the data. The extraction of two statistically meaningful components contrasts with the initial hypothesis that three aspects could be distinguished. The loadings (selected arbitrarily, though somewhat conventionally, at \pm 0.400 ), the percentage of common variance accounted for by each component, and the eigenvalues are given in figure $2 .^{23}$

\footnotetext{
${ }^{23} \mathrm{~A}$ minimum value of 1.00 for an eigenvalue is arbitrarily recognized by many as indicating the significance of a
}

\section{INTERPRETATION OF COMPONENTS}

Component 1 , which accounts for over 51 percent of the common variance in the data, consists of two "attitude" and two "teaching" statements, thereby lending some credence to the idea that images of geography might be expected to be significantly correlated with the way in which the particular course is taught. Basically, this component reveals that students have a positive feeling about characteristics of geography. The responses are usually favorable toward the discipline; for example, geography is not perceived as a discipline disseminating essentially useless information, nor is it one that should be eliminated from the high school curriculum. (See statements 11 and 12.) Indeed, the earlier discussion of mean scores pointed out that these two "teaching" statements evidence the highest positive deviations from the neutral value of 3.00 . In addition, students viewed geography as involving considerably more than memorizing and regurgitating facts (statement 30), a finding substantiated by their indication that geography is a logical subject (statement 24). Thus, it would appear that students generally regard the study of geography as a worthy endeavor that deserves an important role in the American high school curriculum. In short, component 1 may be labeled as a dimension reflecting the intimate relationship

component. Moreover, all significant loadings registered a positive sign, as the scoring system would suggest, although, of course, many of the nonsignificant ones were negative. 
between the attitudes toward and the teaching of a discipline.

Component 2 has been designated as a "knowledge" dimension because it consists exclusively of three "knowledge" statements. Furthermore, it accounts for a respectable 13.3 percent of the remaining variance in the data matrix. A particularly important finding from the components analysis, which the earlier examination of individual mean values did not elicit, is that the highest loading of the three variables in this component pertains to student observations about geography's primary concern with the explanation of various locations (statement 9). This result undoubtedly will be welcome news to geographers. A further indication of the ability of students to effectively discriminate about the content of the subject matter is revealed by responses to statements 1 and 2. The responses showed that students were largely aware that the study of geography entails considerably more than drawing maps and explaining physical phenomena.

\section{CONCLUSIONS}

The intent of this research was to measure the images that high school students in Nebraska have about geography. A Likert-type schedule containing 30 statements relating to geography was used as a method of collecting raw data on the students' opinions. Some of the more definite attitudes about geography were revealed by quantifying the responses on a five-point scale. In general, the sampled students believed that geography involves more than memorizing placenames, is more than just drawing maps, and helps in understanding current affairs. They believed it is a logical, useful subject that should be taught in high school.

The data also were subjected to a principal components analysis in an effort to extract meaningful dimensions underlying the students' images of geography. We anticipated and hypothesized that such an analysis would yield three components: a "knowledge," a "teaching," and an "attitude" component; however, only two meaningful components resulted. Only one-the "knowledge" factor-accorded entirely with our expectations. The other component-attitude and teaching-indicated that a fairly intimate relationship exists between the teaching of geography and favorable attitudes about the discipline's usefulness and its importance as a high school subject.

The dominant image portrayed by the high school respondents may tentatively be regarded as positive. This suggests that misconceptions about geography so frequently encountered at the post-secondary level may be more common among students who do not take a formal geography course in high school than among those who do study geography. To verify this, of course, would require investigating a different population. 